\title{
Viabilidade do uso de placas de granito como lajes em edificações
}

\author{
Feasibility of using granite plates as building slabs
}

\section{Sérgio Trajano Franco Moreiras Antenor Braga Paraguassú}

\section{Resumo}

$\mathbf{P}$

lacas de granitos são amplamente empregadas no revestimento de pisos na forma de ladrilhos assentados com argamassa industrializada. Recentemente, tem crescido o interesse no uso de sistemas não aderentes (sem argamassa) com placas de rocha. Porém, na literatura muito pouco foi publicado a respeito. O presente trabalho avaliou as propriedades físico-mecânicas de três granitos com grande aceitação comercial, e determinou as espessuras necessárias para estas das placas serem usadas como lajes de $200 \mathrm{~cm}$ de largura por $300 \mathrm{~cm}$ de comprimento, apoiadas pelas quatro extremidades em vigas de concreto. As propriedades testadas para o projeto estrutural das placas de granito foram: resistência à compressão, resistência à flexão por três pontos, módulo de elasticidade e coeficiente de Poisson. Foram também determinados o coeficiente de atrito e a resistência à abrasão profunda para a avaliação do desempenho do piso, de acordo com o uso e o ambiente de exposição,. Os resultados indicaram que o charnockito Verde Labrador deve ser usado com espessura de $30 \mathrm{~mm}$, restrita a ambientes internos. O sienogranito e o monzogranito podem ser empregados em ambientes internos e externos. As placas do monzogranito Cinza Castelo devem possuir espessura de $20 \mathrm{~mm}$, e as do sienogranito Vermelho Brasília devem possuir $30 \mathrm{~mm}$ de espessura.

Sérgio Trajano Franco Moreiras Departamento de Geotecnia, Escola de Engenharia de São Carlos Universidade de São Paulo Av. Trabalhador São Carlense, 400, São Carlos - SP - Brasi CEP 13566-590 Tel.: (16) 3373-9501 E-mail: strajano@gmail.com

Antenor Braga Paraguassú Departamento de Geotecnia, Escola de Engenharia de São Carlos Universidade de São Paulo Av. Trabalhador São Carlense, 400, Sao Carlos - SP - Brasil CEP 13566-590

Tel.: (16) 3373-9490 Ramal 9494 E-mail: nonus@sc.usp.br

Recebido em 30/10/11 Aceito em 03/10/12
Palavras-chave: Granitos. Revestimento de pisos. Sistemas não aderentes.

\section{Abstract}

Granite plates are largely used as floor finishings, in the form of tiles settled on a thin layer of industrialized mortar. Recently, there has been growing interest on using this such plates as non-adherent systems, i.e. without mortar. However, very little has been published in the literature on that topic. This study has evaluated the mechanical properties of three types of granites with great commercial acceptance, and also determined the necessary thickness for this type of plates to be used as slabs of $200 \mathrm{~cm}$ wide and $300 \mathrm{~cm}$ long, supported on the four edges by concrete beams. The properties tested for the structural design of the granite plates were: compressive strength, flexural strength, modulus of elasticity and Poisson's ratio., The abrasion resistance and the slip resistance were also tested, in order to evaluate the performance of the plates as floor finishings, considering the use and the environmental conditions. The results indicated that charnockite should used with $30 \mathrm{~mm}$ of thickness, only for indoor uses. The syenogranite and the monzogranite should be used for both indoor and external uses. The thickness of monzogranite slabs should be $20 \mathrm{~mm}$ and the thickness of syenogranite slabs should be $30 \mathrm{~mm}$.

Keywords: Granites. Floor finishings. Non-adherent system. 


\section{Introdução}

A produtividade da indústria da construção civil brasileira é pequena se comparada com a de outros países. Dados da Federação das Indústrias do Estado de São Paulo (Fiesp) mostram que a produtividade média do trabalhador brasileiro em dólares americanos é de cinco a sete vezes menor do que a dos europeus e americanos; e o prazo médio de execução das obras é de duas a três vezes maior (FEDERAÇÃO..., 2008).

Um exemplo dessa baixa produtividade é a execução das vedações verticais, que, em cerca de $96 \%$ das obras, são executadas com blocos cerâmicos ou blocos de concreto. Outro dado é que mais de 70\% das lajes de habitações de médio porte no Brasil são realizadas com um sistema misto de blocos cerâmicos, vigas pré-moldadas de concreto, concreto e argamassa; isso sem levar em conta os materiais empregados no revestimento do piso (FEDERAÇÃO..., 2008).

Esse sistema empregado para a construção de lajes leva um tempo razoavelmente longo para ser construído, exige um número elevado de horas trabalhadas, além de gerar desperdício de material em comparação com os métodos que empregam placas pré-fabricadas.

$\mathrm{Na}$ busca por inovações tecnológicas, que racionalizem a construção de lajes em edificações, o presente artigo estuda a viabilidade do emprego de placas de rocha como lajes de edificações. Dos diversos tipos litológicos existentes foi selecionado o grupo dos granitos, devido a sua alta durabilidade e resistência mecânica.

Os granitos comercializados em placas genericamente englobam diversos tipos de rochas como os granitos propriamente ditos, os gnaisses, os monzonitos, os dioritos, os sienitos, os charnockitos, entre outros. Eles têm alto valor comercial devido à alta durabilidade e à grande diversidade de padrões de designs e de tonalidades das placas com acabamento polido. As variedades litológicas existentes são originárias das diversas formações geológicas brasileiras. Os desenhos formados nas placas evidenciam as características mineralógicas, texturais e estruturais que se relacionam aos processos de formação da rocha.

O Brasil, em 2010, extraiu 3,9 milhões de toneladas de blocos de granito para a produção de chapas. Desse total, cerca de 65 milhões de metros quadrados de chapas foram consumidos pelo mercado interno (ROCHAS..., 2011).

A aplicação de placas pétreas como laje de edificações apresenta uma significativa racionalização dos serviços e uma redução nos custos com a mão de obra. Nesse sentido, o presente artigo emprega metodologia para $o$ dimensionamento das placas de rocha com base no critério das tensões admissíveis, na teoria elástica das estruturas em placas e nas características físico-mecânicas da rocha. Também avalia o desempenho do piso por intermédio dos ensaios de resistência à abrasão profunda e determinação do coeficiente de atrito.

\section{Sistemas não aderentes}

\section{Justificativa}

A proposta deste artigo é utilizar placas de granitos, com acabamento polido, como lajes das edificações. Não é utilizada argamassa para fixação, sendo as placas apoiadas pelas quatro extremidades em sistemas de vigas de concreto (Figura 1).

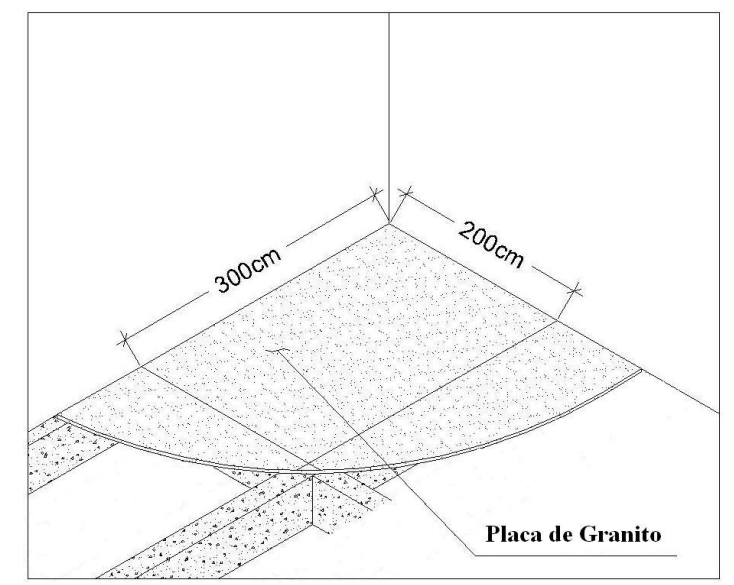

Figura 1 - Sistema não aderente de revestimento de pisos com placas polidas de granito com comprimento de $300 \mathrm{~cm}$ e largura de $200 \mathrm{~cm}$ 
O tamanho das placas selecionado para laje estrutural foi de $200 \mathrm{~cm}$ de largura por $300 \mathrm{~cm}$ de comprimento, pois é o maior tamanho de placa que a indústria nacional fornece sem modificar os equipamentos de beneficiamento empregados. Para esta pesquisa optou-se por apoiar as placas pelas quatro extremidades, pois, em comparação com placas apoiadas apenas pelas duas extremidades, as espessuras obtidas pelo dimensionamento são menores, porque os momentos e tensões internas atuantes são inferiores.

As lajes de granito com espessura de $30 \mathrm{~mm}$ pesam aproximadamente $50 \mathrm{~kg} / \mathrm{m}^{2}$ para mais ou para menos, dependendo do tipo litológico em questão. As lajes convencionais pré-fabricadas encontradas no mercado pesam por volta de 200 $\mathrm{kg} / \mathrm{m}^{2}$, sem contar com a execução do contrapiso e do acabamento. Ainda complementando essa comparação, as placas de rocha permitem, em média, uma sobrecarga duas vezes maior em relação aos sistemas convencionais.

Os vãos de dois e três metros para vigas são considerados pequenos em comparação com sistemas tradicionais com lajes pré-moldadas, que geralmente obtêm vãos de 3 a 4 metros. Porém, isso não representa uma desvantagem, pois o sistema com placa de rocha é em média $150 \mathrm{~kg} / \mathrm{m}^{2}$ mais leve, resultando em pilares e vigas mais esbeltos e com menor taxa de armação.

\section{Aspectos construtivos}

Seguindo a modulação de dois por três metros das placas de rocha, os ambientes podem ter as seguintes dimensões: $2 \mathrm{~m}$ x $3 \mathrm{~m}, 2 \mathrm{~m}$ x $6 \mathrm{~m}, 3 \mathrm{mx}$ $4 \mathrm{~m}, 3 \mathrm{~m} \times 6 \mathrm{~m}, 4 \mathrm{~m} \times 6 \mathrm{~m}, 4 \mathrm{~m} \times 9 \mathrm{~m}, 6 \mathrm{~m} \times 6 \mathrm{~m}$, $6 \mathrm{~m} \times 8 \mathrm{~m}$ e assim por diante. Outros tamanhos de piso, fora da modularização proposta, podem ser empregados aplicando-se a metodologia presente, porém o sistema perderá a racionalização obtida.

Nesse sistema de fixação é necessária a instalação de uma camada de neoprene entre as vigas e as placas. De acordo com a norma brasileira ABNT NBR 9062 (ABNT, 2006) - Projeto e execução de estruturas de concreto pré-moldado - para o caso em questão deve-se especificar uma camada de neoprene com espessura mínima de $6 \mathrm{~mm}$ e dureza Shore A 70.

As juntas devem ser dimensionadas entre as placas e entre elas e as paredes da edificação, para permitir as dilatações causadas pelas variações térmicas e também acomodar os desvios dimensionais das placas que ocorrem durante sua produção. Aplicando-se o procedimento da norma ABNT NBR 15845 (ABNT, 2010a) - Rochas para revestimento: Métodos de Ensaio (Anexo C Coeficiente de dilatação térmica linear) - para os três tipos litológicos estudados, o valor da deformação térmica da rocha obtida é menor do que $1 \mathrm{~mm}$ nos dois sentidos das placas, considerando uma variação térmica de $50{ }^{\circ} \mathrm{C}$. De acordo com as normas EN 1341 (EUROPEAN..., 2001a) e EN 12058 (EUROPEAN..., 2004), a tolerância permitida no comprimento e na largura de placas com $200 \mathrm{~cm}$ por $300 \mathrm{~cm}$ é de $1,5 \mathrm{~mm}$ para mais ou para menos. Portanto, para acomodar as variações dimensionais e térmicas, especifica-se uma junta com $4 \mathrm{~mm}$ de largura.

Para proteger a placa de rocha contra a infiltração de água, deve ser aplicado nas juntas um selante do tipo elástico, que permite as deformações da pedra sem ocorrer a ruptura do selante, sendo este colocado sobre um cordão flexível de polietileno (Figura 2).

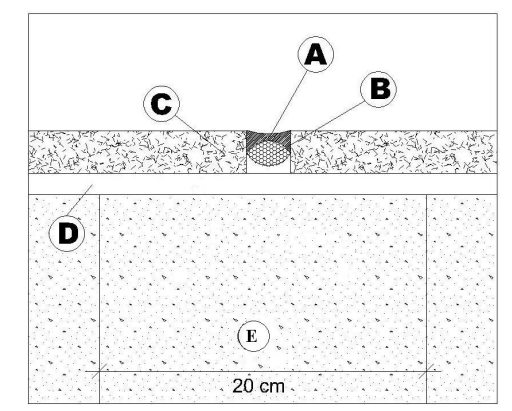

Figura 2 - Detalhes do sistema não aderente de pisos com placas pétreas Nota: Legenda:

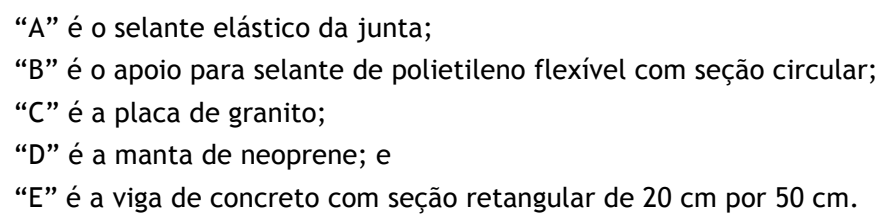


A tolerância permitida de $3 \mathrm{~mm}$ a mais ou a menos pela norma EN 1341 (EUROPEAN..., 2001a) para a espessura da placa pode gerar desníveis. Portanto, para produzir placas sem variação significativa na espessura deve-se empregar equipamentos diamantados multifios ou retíficas.

As placas dos três granitos estudados Vermelho Brasília, Verde Labrador e Cinza Castelo com 20 $\mathrm{mm}$ de espessuras pesam, respectivamente, 314,5 $\mathrm{kg}, 321,0 \mathrm{~kg}$ e $319 \mathrm{~kg}$, e as com $30 \mathrm{~mm}$ pesam, respectivamente, $472,0 \mathrm{~kg}, 482,0 \mathrm{~kg}$ e $478,0 \mathrm{~kg}$.

As placas antes da montagem devem ser verificadas quanto à ausência de trincas, veios, nichos constituintes de outros minerais e outras características que possam prejudicar o desempenho estrutural da placa. A equipe de montagem deve ter conhecimento em transporte vertical e horizontal com placas pétreas ou cimentícias, instalação de manta de neoprene e aplicação de selantes em juntas. Para a montagem das placas, devem empregados talhas mecânicas ou equipamentos similares, com capacidade mínima de uma tonelada. Esses equipamentos, na maior parte dos casos, são fornecidos pela equipe de montagem.

\section{Viabilidade econômica}

Para simulação do orçamento por metro quadrado de área construída foi considerada a construção de uma sala de $4 \mathrm{~m}$ de largura por $6 \mathrm{~m}$ de comprimento, com piso formado por quatro placas de rocha. Em seguida o orçamento foi comparado com aquele do sistema de lajes pré-fabricadas/prémoldadas convencionais. A composição dos custos foi obtida na Tabela de Composições de Preços para Orçamentos (TABELA..., 2011) e no Guia da Construção (2012), que consideram impostos e taxas referentes aos materiais e serviços, e desconsideram taxas referentes aos benefícios e despesas indiretas (BDI).
As juntas entre placas e entre elas e as paredes possuem $4 \mathrm{~mm}$ de largura e $4 \mathrm{~mm}$ de profundidade. Para a área em questão, de $24 \mathrm{~m}^{2}$, essas juntas totalizam $30 \mathrm{~m}$ lineares. $\mathrm{O}$ neoprene possui largura de $10 \mathrm{~cm}$ e é instalado ao longo do perímetro da placa. Os preços de placas com 30 $\mathrm{mm}$ de espessura, incluindo os custos com transporte para o município de São Paulo, para os granitos Vermelho Brasília, Verde Labrador e Cinza Castelo são, respectivamente, de R\$ $173,00 / \mathrm{m}^{2}, \mathrm{R} \$ 95,00 / \mathrm{m}^{2}$ e $\mathrm{R} \$ 106,00 / \mathrm{m}^{2}$.

A Tabela 1 apresenta os custos dos materiais por metro quadrado de piso para o sistema com placas pétreas em questão, incluindo também a aplicação de forro de gesso na parte inferior do sistema.

Para o cálculo da mão de obra considera-se que uma equipe composta de três montadores instala a camada de neoprene, realiza a montagem das placas e aplica o selante em um período de $8 \mathrm{~h}$. Assim sendo, em 24 h.homem trabalhadas são executados $24 \mathrm{~m}^{2}$, ou seja, 1 h.homem por metro quadrado de piso. Considerando o custo do montador, que é R\$ $15,00 / \mathrm{m}^{2}$, e da aplicação do gesso, em R\$10,84, o custo total de mão de obra é de R\$ 25,84. Somados ao custo das placas dos granitos, teremos um custo total de $\mathrm{R} \$ 230,40 / \mathrm{m}^{2}$ para o Vermelho Brasília, de $\mathrm{R} \$ 152,40 / \mathrm{m}^{2}$ para o Verde Labrador e R $\$ 163,40 / \mathrm{m}^{2}$ para o Cinza Castelo. Nesse cálculo são desconsiderados os custos com talhas mecânicas para a movimentação das placas, serviço que é fornecido pela equipe de montagem.

Para a execução de lajes pré-moldadas convencionais no padrão de médio porte são necessárias as seguintes operações: montagem das vigas pré-moldadas, instalação das lajotas cerâmicas, concretagem da laje, regularização do piso, instalação do revestimento cerâmico, além da aplicação de chapisco, de reboco, de massa fina e a pintura da parte inferior da laje. O custo total para execução é de $\mathrm{R} \$ 166,44 / \mathrm{m}^{2}$, sendo $\mathrm{R} \$ 69,30 / \mathrm{m}^{2}$ de material e $\mathrm{R} \$ 97,14$ de mão de obra.

Tabela 1 - Custo por metro quadrado do sistema de lajes com placas de granito

\begin{tabular}{l|c|r}
\hline \multicolumn{1}{c|}{ Componente } & Quantidade $/ \mathbf{m}^{\mathbf{2}}$ de piso & Custo/m $\mathbf{m}^{\mathbf{2}}$ \\
\hline Vermelho Brasília $30 \mathrm{~mm}$ & $1 \mathrm{~m}^{2}$ & 173,00 \\
Verde Labrador $30 \mathrm{~mm}$ & $1 \mathrm{~m}^{2}$ & 95,00 \\
Cinza Castelo $30 \mathrm{~mm}$ & $1 \mathrm{~m}^{2}$ & 106,00 \\
Neoprene & $0,17 \mathrm{~m}^{2}$ & 18,00 \\
Selante & $50 \mathrm{~g}$ & 4,60 \\
Apoio do selante & $1,25 \mathrm{ml}$ & 0,50 \\
Gesso & $1 \mathrm{~m}^{2}$ & 8,46 \\
TOTAL Vermelho Brasília & & 204,56 \\
TOTAL Verde Labrador & & 126,56 \\
TOTAL Cinza Castelo & & 137,56 \\
\hline
\end{tabular}

28 Moreiras, S. T. F.; Paraguassú, A. B. 
Dois dos três granitos estudados (Verde Labrador e Cinza Castelo) apresentaram custos semelhantes ao dos sistemas convencionais de execução de lajes. O Vermelho Brasília apresentou um custo adicional de $\mathrm{R} \$ 63,96 / \mathrm{m}^{2}$. As principais vantagens do sistema são a redução dos custos com mão de obra em até quatro vezes, das horas trabalhadas em até quatro vezes e do tempo total para execução da laje.

\section{Materiais e métodos}

\section{Materiais}

A escolha dos tipos de rocha foi feita levando-se em conta a ampla aceitação comercial, os padrões estéticos e as propriedades físico-mecânicas dentro dos requisitos estabelecidos para granitos pela norma ABNT NBR 15844 (ABNT, 2010b). Foram selecionados três granitos "brasileiros" (Figura 3), um sienogranito (Vermelho Brasília), um charnockito (Verde Labrador) e um monzogranito (Cinza Castelo). Essas rochas são lavradas, respectivamente, nos municípios de Japuaci (GO), Baixo Guandu (ES) e Castelo (ES).
A análise petrográfica das três rochas foi obtida em Ribeiro, Paraguassú e Rodrigues (2008) e seguiu as diretrizes da norma ABNT NBR 15845 (ABNT, 2010c) (Anexo A). Ela fornece dados sobre a mineralogia, o grau de fissuramento e a alteração mineral (Figura 4). Esses são indicativos para avaliação se determinado tipo litológico é susceptível ao uso em ambientes externos e/ou em áreas úmidas (MOREIRAS, 2005).

O sienogranito Vermelho Brasília tem estrutura isotrópica e inequigranular, com os grãos variando de $2 \mathrm{~mm}$ a $30 \mathrm{~mm}$. Os minerais essenciais são quartzo $(32,0 \%)$, microclínio $(41,0 \%)$, oligoclásio $(16,0 \%)$ e biotita $(5,0 \%)$. Esse "granito" apresenta alto grau de coesão, baixo grau de microfissuramento e alteração mineral em grau de fraco para moderado.

O charnockito Verde Labrador é isotrópico, os grãos variam de $2 \mathrm{~mm}$ a $25 \mathrm{~mm}$. Os minerais essenciais são quartzo $(14,0 \%)$, microclínio $(39,0 \%)$, oligoclásio $(19,0 \%)$, biotita $(5,0 \%)$, hiperstênio $(5,0 \%)$, hornblenda $(5,0 \%)$ e granada $(5,0 \%)$. O grau de alteração mineral e de microfissuramento são de moderado para intenso.

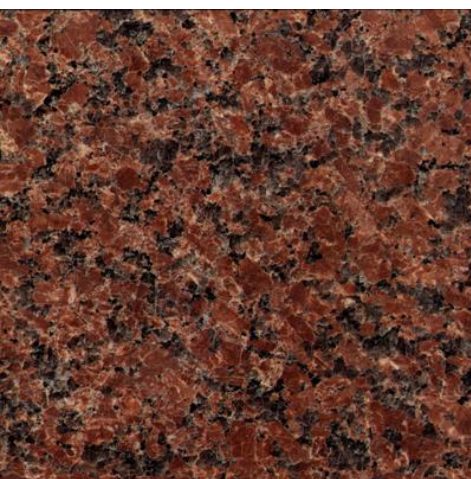

(a) sienogranito Vermelho Brasília

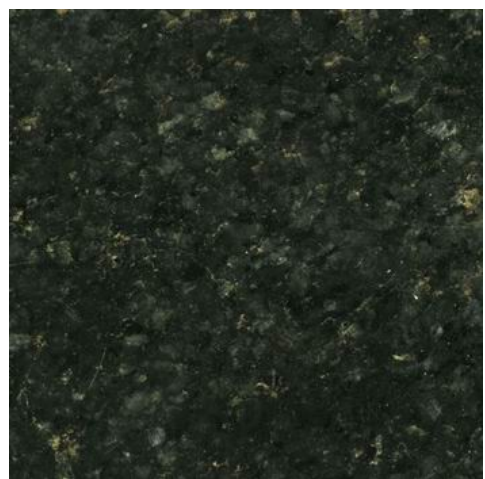

(b) charnockito Verde Labrador

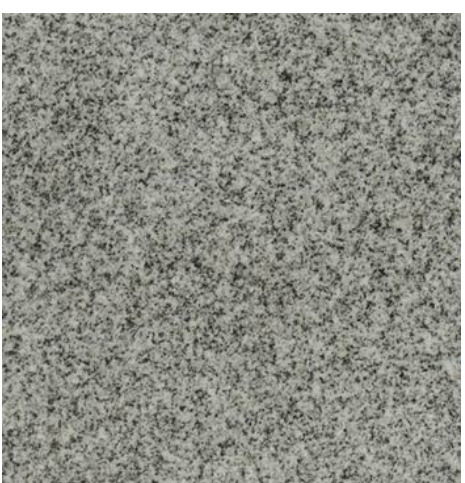

(c) monzogranito Cinza Castelo

Figura 3 - Aparência macroscópica dos granitos estudados - ladrilhos de $40 \mathrm{~cm}$ x $40 \mathrm{~cm}$ Fonte: Abirochas (ASSOCIAÇÃO..., 2002).

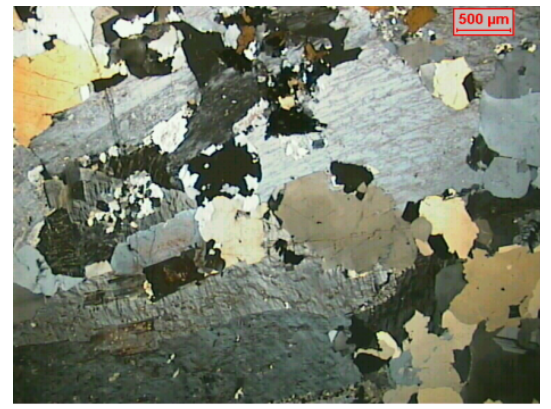

(a) Vermelho Brasília

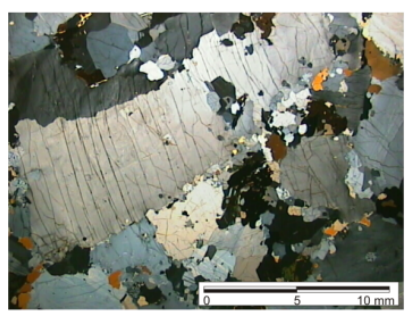

(b) Verde Labrador (notar o intenso microfissuramento)

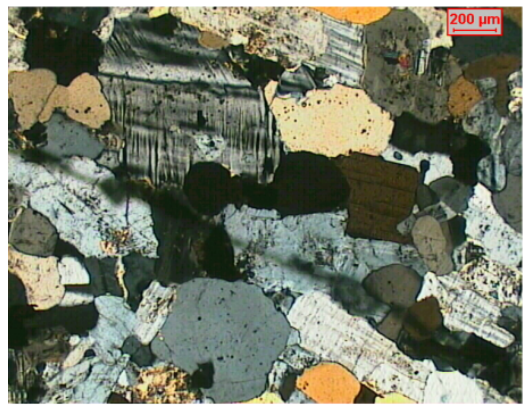

(c) Cinza Castelo

Figura 4 - Fotomicrografia dos granitos 
O monzogranito Cinza Castelo possui estrutura equigranular, com variação do tamanho dos grãos minerais de $2 \mathrm{~mm}$ a $25 \mathrm{~mm}$. Os minerais essenciais são quartzo $(29,0 \%)$, microclínio $(39,0 \%)$, plagioclásio $(22,5 \%)$ e biotita $(8,0 \%)$. O grau de microfissuramento e de alteração mineral são fracos.

\section{Caracterização tecnológica}

A seguir são apresentados os procedimentos dos ensaios empregados na obtenção das características tecnológicas dos granitos para pisos em sistemas não aderentes.

\section{Módulo de ruptura}

O ensaio de módulo de ruptura, também conhecido por resistência à flexão por três pontos, seguiu as diretrizes do Anexo $\mathrm{F}$ da norma ABNT 15845 (ABNT, 2010d) - Rochas para revestimento Métodos de ensaio. As amostras devem possuir 50 $\mathrm{mm}$ de espessura, $100 \mathrm{~mm}$ de largura e $200 \mathrm{~mm}$ de comprimento. Os corpos de prova ficam apoiados sobre dois roletes com vão de $180 \mathrm{~mm}$, sendo um articulado e outro não. Outro rolete articulado faz o carregamento na linha central superior da amostra a uma taxa de carregamento de 4.450 $\mathrm{N} /$ min até que ocorra a ruptura da amostra. Com a carga de ruptura $(\mathrm{P})$ calcula-se a tensão $\left(\sigma_{t}\right)$ na ruptura pela Equação 1:

$\sigma_{\mathrm{t}}=3 \mathrm{PL} / 2 \mathrm{bd}^{2}(\mathrm{MPa})$

Eq. 1

Onde:

"L” é o vão do ensaio;

"b" é a largura do corpo de prova; e

"d" é a altura do corpo de prova.
Os três granitos em questão possuem estrutura homogênea e devem ser ensaiados no mínimo cinco corpos de prova. O resultado final será a média desses resultados. Granitos "movimentados", com estruturas heterogêneas, devem ser ensaiados no mínimo com cinco corpos de prova em cada direção da placa.

\section{Resistência à compressão, módulo de elasticidade e coeficiente de Poisson}

Esses ensaios seguiram as diretrizes da norma ASTM D 7012 (AMERICAN..., 2010). Os corpos de prova cilíndricos têm diâmetro de $73,2 \mathrm{~mm}$ e altura variando entre $146,4 \mathrm{~mm}$ e $183,0 \mathrm{~mm}$.

$\mathrm{O}$ procedimento para determinação da resistência uniaxial está presente no método $\mathrm{C}$ da referida norma. O ensaio começa com uma taxa de carregamento de $0,5 \mathrm{MPa} / \mathrm{s}$ a $1,0 \mathrm{MPa} / \mathrm{s}$ até que ocorra a ruptura da amostra. A carga de ruptura é determinada, e a tensão de ruptura é obtida pela Equação 2:

$\sigma_{u}=\frac{P}{A}(\mathrm{MPa})$

Eq. 2

Onde:

“ $\sigma_{\mathrm{u}}$ " é a tensão na ruptura;

"P" é a carga de ruptura; e

"A" é área da seção transversal.

Para a determinação do módulo de elasticidade e do coeficiente de Poisson seguiram-se as diretrizes do método D da norma ASTM D 7012 (AMERICAN..., 2010). A Figura 5 mostra o ensaio para determinação dos deslocamentos axiais e circunferenciais em função do carregamento aplicado.

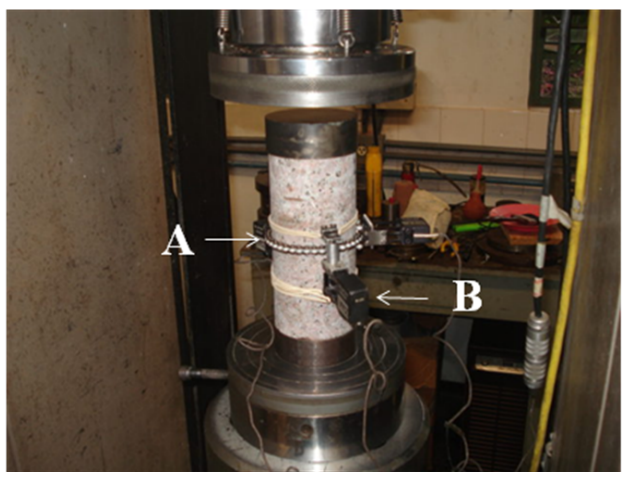

Figura 5 - Ensaio para determinação do módulo de elasticidade na compressão e do coeficiente de deformação circunferencial

Nota: Legenda:

"A" é o sensor para determinação do deslocamento circunferencial; e

“B” é o sensor para determinação do deslocamento longitudinal (o trecho inicial de leitura foi de $50 \mathrm{~mm}$ ). 
Para obter-se o módulo de elasticidade e o coeficiente de Poisson é necessário traçar as curvas tensão versus deformação axial e tensão versus deformação diametral.

As deformações axiais foram obtidas pela Equação (3):

$\varepsilon_{a}=\frac{\Delta L}{L}$

Onde:

" $\varepsilon_{\mathrm{a}}$ " é a deformação axial;

" $\Delta \mathrm{L}$ " é a variação medida ao longo do eixo axial da amostra; e

"L" é o comprimento inicial medido, que no caso foram empregados $50 \mathrm{~mm}$.

As deformações diametrais foram obtidas pela Equação (4):

$\varepsilon_{l}=\frac{\Delta D}{D}$

Onde:

" $\varepsilon_{l}$ " é a deformação diametral;

“ $\Delta \mathrm{D}$ ” é a variação medida lateralmente na amostra; e

"D" é o diâmetro da amostra.

Para transformar os deslocamentos circunferenciais medidos no ensaio em deslocamentos diametrais deve-se dividir o resultado por $\pi$.

Após a aquisição dos dados são traçadas as curvas de tensão versus deformação longitudinal e tensão

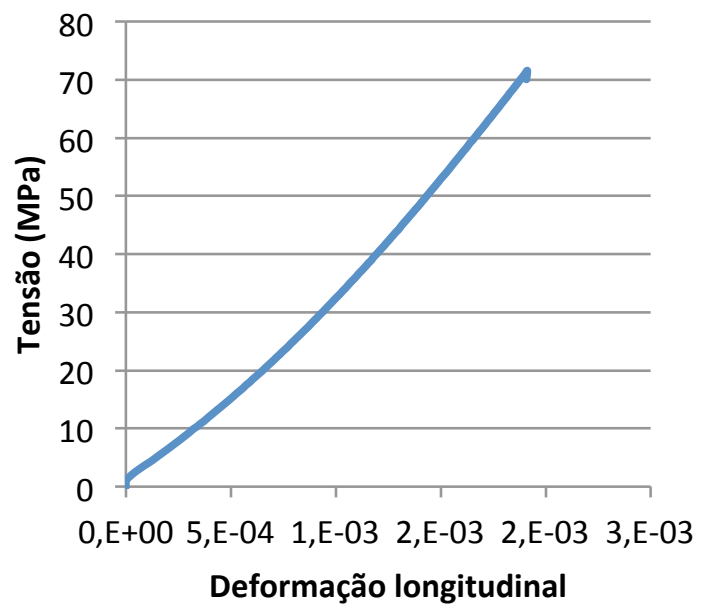

(a) versus deformação radial (Figura 6). O módulo de elasticidade (E) será o coeficiente angular tangente à curva tensão versus deformação longitudinal no ponto correspondente a $50 \%$ da tensão de ruptura. O coeficiente de Poisson é obtido pela razão entre o módulo de elasticidade e coeficiente angular da reta tangente à curva tensão versus deformação radial.

\section{Avaliação de impactos acidentais}

Após a determinação das espessuras das placas pela metodologia a ser apresentada no item 4, avaliam-se os efeitos que eventuais cargas acidentais possam causar no sistema. Para tanto, as placas de $2 \mathrm{~m}$ por $3 \mathrm{~m}$ na espessura de projeto, com acabamento polido, montado sobre manta de neoprene com $6 \mathrm{~mm}$ de espessura, devem ser verificadas quanto à resistência ao impacto de corpo mole e de corpo duro. Para esses ensaios adaptaram-se as diretrizes da norma europeia 12825 (EUROPEAN..., 2001b), que estabelece procedimento para ensaio de impacto de corpo duro e de corpo mole em pisos elevados.

A principal adaptação realizada foi o aumento na energia de impacto, pois impactos de maior energia podem ocorrer no sistema devido à queda de pessoas e objetos de maior peso, causando a ruptura da placa. Na norma a energia de impacto de corpo mole é de 400 joules; para a laje estrutural essa energia foi aumentada para 1.000 joules. Para o impacto de corpo duro a energia de impacto é de 27 joules, e foi aumentada para 100 joules.

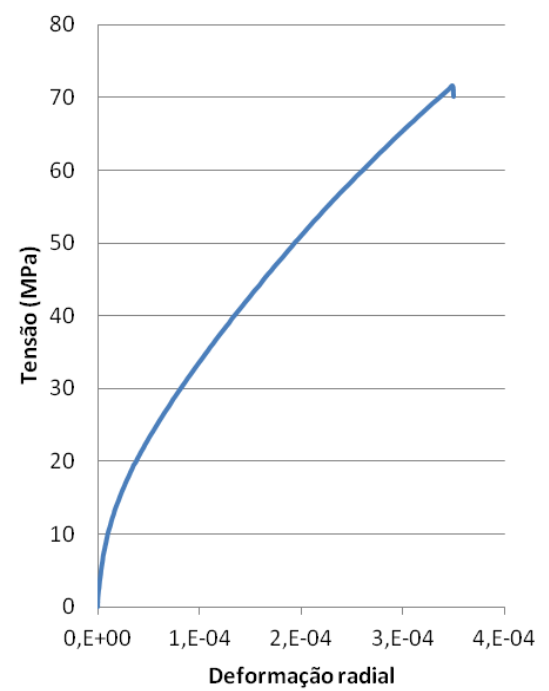

(b)

Figura 6 - (a) Curva média de tensão versus deformação longitudinal do granito Cinza Castelo e (b) curva média de tensão versus deformação radial do granito Cinza Castelo 
Para avaliar o impacto de corpo mole com energia de 1.000 joules, o carregamento é realizado com saco de couro com $30 \mathrm{~cm}$ de diâmetro, massa de $100 \mathrm{~kg}$, preenchido com areia e lançado de uma altura de $100 \mathrm{~cm}$. Dois golpes são executados, um no centro da placa e outro no centro de uma das arestas.

Para avaliar o impacto de um corpo duro com energia de 100 joules, o procedimento prescreve a aplicação de três golpes com corpo duro metálico, com diâmetro de $7,5 \mathrm{~cm}$, massa de $10 \mathrm{~kg}$ e uma altura de queda de $100 \mathrm{~cm}$. O primeiro golpe deve ser aplicado no centro da placa, o segundo, no centro das arestas, e o terceiro, em qualquer região considerada frágil.

A placa é considerada apta para o uso se após esses dois ensaios não houver ruptura, nem a presença de trincas e fissuras. Caso ocorra alguma patologia, as placas deverão ser testadas novamente, com espessura maior.

\section{Abrasão profunda}

Esse ensaio foi inicialmente desenvolvido para a determinação da resistência à abrasão profunda de peças cerâmicas não esmaltadas, sendo atualmente utilizado em rochas ornamentais. Ele segue as diretrizes do Anexo E (determinação da resistência à abrasão profunda) da norma ABNT 13818 (ABNT, 1997a) - Placas para Revestimento: Especificação e métodos de ensaio. Neste ensaio emprega-se um aparelho denominado abrasímetro, constituído de um disco rotativo de aço, uma caixa de armazenagem de material abrasivo, um funil de escoamento para saída do material abrasivo, um

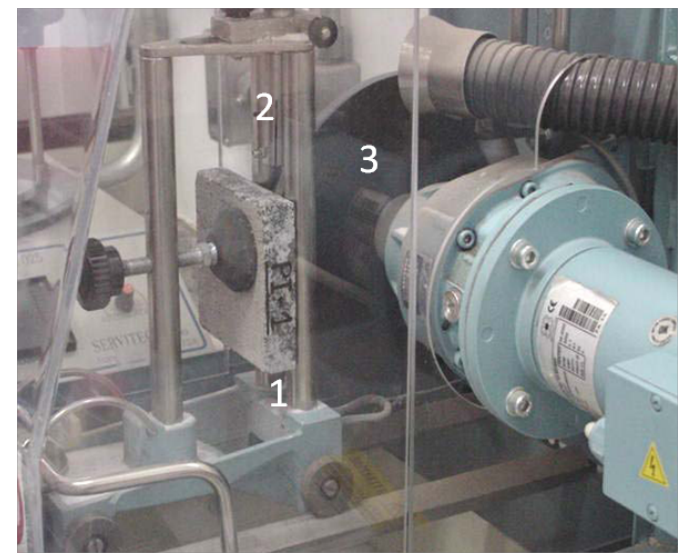

(a) suporte para o corpo de prova e um contrapeso (Figura 7a).

As amostras, depois de lavadas e secas, são fixadas no equipamento, de forma que o disco rotativo fique na perpendicular. A velocidade de rotação é de $75 \pm 5 \mathrm{rpm}$, e o abrasivo é ajustado de maneira a gerar um fluxo uniforme de $100 \pm 0,05 \mathrm{~g}$ a cada $100 \pm 5$ rotações. Após 150 rotações a amostra é retirada, e o volume do material removido (depressão) (Figura 7b) é obtido pelas Equações 5 e 6:

$V=\left(\frac{\pi \times \alpha}{180}-\operatorname{sen} \alpha\right) \times\left(\frac{h \times d^{2}}{8}\right)\left(\mathrm{mm}^{3}\right)$ Eq. 5

Sendo:

$\operatorname{sen} \alpha=\frac{2 \times C_{c a v}}{d}$ Eq. 6

Onde:

"V" é o volume de material removido (mm3);

"d" é o diâmetro do disco rotativo em mm;

" $h$ " é a espessura do disco rotativo em mm;

" $\alpha$ " é o ângulo correspondente ao centro do disco até a cavidade em graus; e

"Ccav" é o comprimento da cavidade em milímetros.

Gonzalez-Mesones (2005) dividem o índice de abrasão profunda em quatro classes, de acordo com a intensidade do tráfego, a partir da dimensão da depressão causada na amostra (Tabela 2).

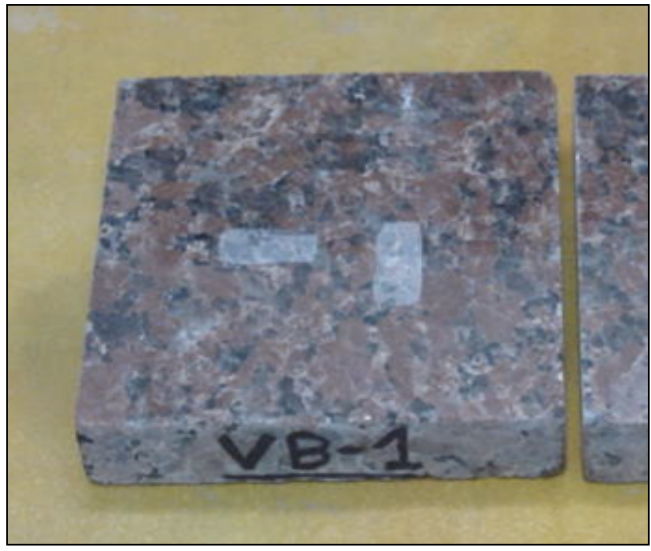

(b)

Figura 7 - (a) Vista do equipamento para ensaio de abrasão profunda e (b) Depressão na amostra após a realização do ensaio

Nota: Legenda:

(1) amostra de granito;

(2) entrada do abrasivo; e

(3) disco giratório que comprime o abrasivo contra a amostra. 
Tabela 2 - Valores mínimos do ensaio de resistência à abrasão profunda em função da intensidade de uso

\begin{tabular}{l|c}
\hline \multicolumn{1}{c|}{ Usos } & Medidas do desgaste Abrasão Profunda \\
\hline Individual & 26 \\
Normal & 24 \\
Coletivo intenso e lento & 22 \\
Coletivo rápido e escada & 20 \\
\hline
\end{tabular}

Fonte: Gonzalez-Mesones (2005).

\section{Determinação do coeficiente de atrito}

No ensaio de determinação do coeficiente de atrito, de acordo com a norma ABNT NBR 13818 (ABNT, 1997b) (Anexo N - Determinação do coeficiente de atrito), um deslizador motorizado do tipo "Tortus", empregado para medir rugosidades de superfície, percorre uma pista com dimensões de $250 \mathrm{~mm} \times 1.000 \mathrm{~mm}$ (Figura 8). Devem ser realizadas no mínimo três leituras ao longo do trecho, cada uma com comprimento mínimo de $150 \mathrm{~mm}$. As juntas entre ladrilhos devem ser identificadas, e as leituras obtidas nesse ponto devem ser descartadas dos resultados.

Essa norma ainda traz a classificação do Transport Road Research Laboratory, pela qual superfícies com coeficiente de rugosidade menor que 0,4 são adequadas para ambientes de usos normais, e as maiores ou iguais a 0,4 são aptas para ambientes onde se requer resistência ao escorregamento.

\section{Resultados}

A Tabela 3 apresenta os resultados da caracterização tecnológica. Os ensaios de módulo de ruptura, módulo de elasticidade e coeficiente de Poisson são empregados no dimensionamento estrutural, para a determinação da espessura das placas e do deslocamento vertical no centro da laje. Os ensaios de abrasão profunda e de determinação do coeficiente de atrito, ambos obtidos em Ribeiro, Paraguassú e Rodrigues (2008), indicam as situações em que o tipo litológico em estudo pode ser empregado quanto à resistência ao escorregamento e à intensidade de tráfego.

\section{Dimensionamento estrutural}

As ações atuantes nas placas foram definidas pela Equação 7 (ELLINGWOOD; GALAMBOS, 1982):

$q=\psi_{i} * G+\psi_{i i} * Q$

Eq. 7

Onde:

"q" é a carga distribuída atuante;

" $\psi_{i}$ " é o coeficiente de segurança parcial para carga permanente (peso próprio);
" $\psi_{\text {ii }}$ " é o coeficiente de segurança parcial para cargas acidentais (sobrecarga);

"G" é o peso próprio; e

“Q” é a carga acidental.

Para " $\psi_{i}$ " foi definido o valor de 1,05 , e para " $\psi_{i}$ ", o valor de 1,00. Para a carga acidental foi empregado o valor de $3 \mathrm{KN} / \mathrm{m}^{2}$.

$\mathrm{Na}$ teoria das placas, ao contrário das estruturas em viga, os esforços atuam nas duas direções da placa, portanto os momentos máximos atuantes devem ser calculados para os dois eixos. As Equações 8 e 9 apresentam os máximos momentos atuantes nas placas, $M_{1 \max }$ e $\mathbf{M}_{2 \max }$, para a situação de placas apoiadas pelas quatro extremidades:

$M_{I M A X}=\beta_{1} * q * a^{1}$

Eq. 8

$M_{2 M A X}=\beta_{2} * q * a^{2}$

Eq. 9

Onde " $\beta_{1}$ " e " $\beta_{2}$ " são coeficientes tabelados em Timoshenko (1977) e valem respectivamente 0,0812 e 0,0500 , e "a" é a largura da placa. Os máximos momentos determinados no centro da placa são $M_{1 \max }=1,2992 \mathrm{KN}$.m e $\mathrm{M}_{2 \max }=0,8000$ KN.m.

As espessuras " $t_{1}$ " e " $t_{2}$ " são determinadas pelas Equações 10 e 11:

$t_{1}=\sqrt{\frac{6^{*} M_{1}}{b^{*} \sigma_{a}}}$

Eq. 10

$t_{2}=\sqrt{\frac{6^{*} M_{2}}{a^{*} \sigma_{a}}}$

Onde:

"a" e "b" são, respectivamente, o menor e o maior lado da placa; e

" $\sigma_{a}$ " é a tensão admissível, obtida dividindo-se o módulo de ruptura pelo coeficiente de segurança.

Na prática, para granitos, o valor geralmente usado é 3 (LEWIS, 1995). A espessura final " $t_{\mathrm{f}}$ " será o maior valor entre essas duas espessuras. A espessura comercial " $t_{\text {com" }}$ " será $o$ valor comercialmente fornecido acima da espessura final calculada. 
Timoshenko e Woinowsky-Krieger (1959) apresentam a Equação 12 para determinar a rigidez à flexão das placas, que é empregada na Equação 13 para determinar a deflexão no centro de placas apoiadas nos quatro lados.

$$
\begin{aligned}
& D=\frac{E^{*} t_{c o m}{ }^{3}}{12\left(1-\mu^{2}\right)} \\
& \partial=4 * \frac{q^{*} a^{4}}{\pi^{6} * D}
\end{aligned}
$$

Onde:
"D" é a rigidez à flexão da placa;

"E" é o módulo de elasticidade;

" $\mathrm{t}_{\text {com }}$ " é a espessura comercial utilizada;

" $\mu$ " é o módulo de Poisson;

“ $\delta$ " é o deslocamento vertical da placa;

"a" é o menor lado da placa; e

"q" é a carga distribuída,

A Tabela 4 apresenta os parâmetros estruturais para o dimensionamento da espessura das placas de granito.

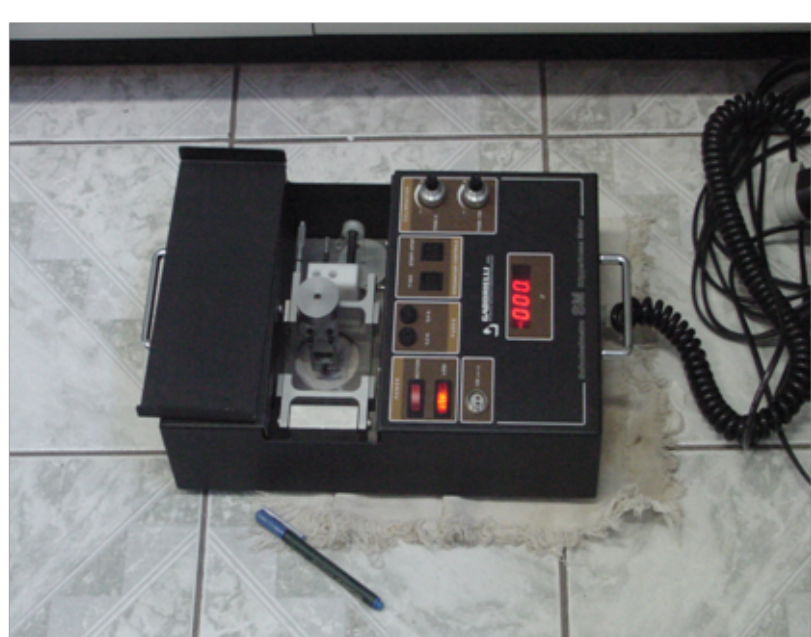

(a)

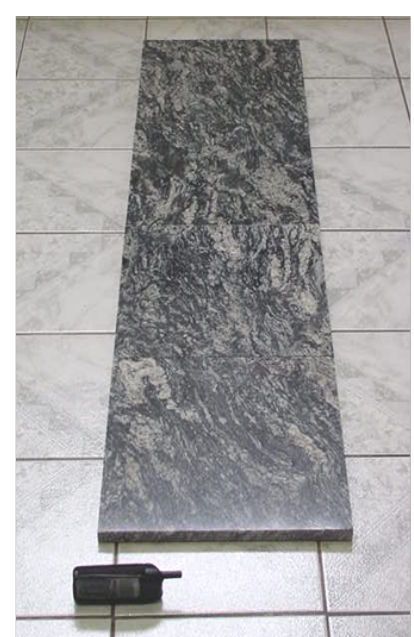

(b)

Figura 8 - (a) Equipamento para medição da rugosidade de superfícies e (b) Pista de 250 mm por 1.000 $\mathrm{mm}$ formada de ladrilhos de granito

\begin{tabular}{|c|c|c|c|c|}
\hline \multirow[b]{2}{*}{ Parâmetros } & \multirow[b]{2}{*}{ Norma } & \multicolumn{3}{|c|}{ Rocha } \\
\hline & & $\begin{array}{c}\text { Vermelho } \\
\text { Brasília } \\
\end{array}$ & $\begin{array}{c}\text { Verde } \\
\text { Labrador } \\
\end{array}$ & $\begin{array}{c}\text { Cinza } \\
\text { Castelo } \\
\end{array}$ \\
\hline $\mathrm{RC}(\mathrm{MPa})$ & ASTM D 7012 (AMERICAN..., 2010) & 209,86 & 183,18 & 214,73 \\
\hline RF (MPA) & ABNT NBR 15845 (Anexo F) (ABNT, 2010d) & 11,85 & 11,29 & 18,97 \\
\hline$v$ & ASTM D 7012 (AMERICAN..., 2010) & 0,23 & 0,35 & 0,31 \\
\hline $\mathrm{E}(\mathrm{GPa})$ & ASTM D 7012 (AMERICAN..., 2010) & 58,37 & 41,29 & 47,95 \\
\hline$\rho\left(\mathrm{kg} / \mathrm{m}^{3}\right)$ & ABNT NBR 15845 (Anexo B) (ABNT, 2010c) & $2.621,00$ & $2.677,00$ & $2.657,00$ \\
\hline IRC & ABNT NBR 13818 (Anexo N) (ABNT, 1997b) & 0,49 & 0,36 & 0,41 \\
\hline $\mathrm{AP}(\mathrm{mm})$ & ABNT NBR 13818 (Anexo E) (ABNT, 1997a) & 24,40 & 22,60 & 27,60 \\
\hline
\end{tabular}

Tabela 3 - Resultados da caracterização tecnológica dos granitos estudados

Nota: Legenda:

"RC" é a resistência à compressão uniaxial;

"RF" é a resistência à flexão por três pontos;

"v" é o coeficiente de Poisson;

"E" é o módulo de elasticidade;

" $\rho$ " é a massa específica;

"IRC" é o índice de resistência ao escorregamento; e

"AP" é a abrasão profunda.

Tabela 4 - Dimensionamento estrutural da espessura das placas de granito

34 Moreiras, S. T. F.; Paraguassú, A. B. 


\begin{tabular}{|c|c|c|c|c|c|c|c|c|}
\hline "Granito" & $\mathbf{q}$ & $\begin{array}{c}\sigma_{\mathrm{a}} \\
(\mathrm{MPa}) \\
\end{array}$ & $\begin{array}{l}{ }^{6} \mathrm{t}_{1}{ }^{\prime} \\
(\mathrm{cm}) \\
\end{array}$ & $\begin{array}{l}\text { "6t, } \\
(\mathbf{c m}) \\
\end{array}$ & $\begin{array}{l}{ }^{"} \mathrm{t}_{\mathrm{f}} " \\
(\mathrm{~cm})\end{array}$ & $\begin{array}{c}\text { "t } t_{\text {com }} " \\
(\mathrm{~cm})\end{array}$ & $\begin{array}{c}\text { "'D" } \\
(\mathrm{KN} / \mathrm{m}) \\
\end{array}$ & $\begin{array}{c}\delta \\
(\mathrm{mm}) \\
\end{array}$ \\
\hline Vermelho Brasília & 3,79 & 3,984 & 2,5 & 2,4 & 2,5 & 3,0 & 158,96 & 1,68 \\
\hline Verde Labrador & 3,80 & 3,753 & 2,6 & 2,5 & 2,6 & 3,0 & 78,52 & 3,39 \\
\hline Cinza Castelo & 3,54 & 6,324 & 1,9 & 1,8 & 2,0 & 2,0 & 29,00 & 7,54 \\
\hline
\end{tabular}

Nota: Legenda:

$$
\begin{aligned}
& \sigma_{\mathrm{a}} \text { é a tensão admissível; } \\
& \text { " } \mathrm{t}_{1} \text { " e " } \mathrm{t}_{2} \text { " são as espessuras calculadas; } \\
& \text { " } \mathrm{t}_{\mathrm{f}} \text { " é a espessura final calculada; } \\
& \text { " } \mathrm{t}_{\mathrm{com}} \text { " é a espessura comercial aplicada; } \\
& \text { " } \mathrm{D} \text { " é a rigidez à flexão da placa, e } \\
& \text { " } \delta \text { " é o deslocamento no centro da placa. }
\end{aligned}
$$

As aberturas nas placas para a passagem de instalações hidráulico-sanitárias, shafts e outras devem passar por avaliação estrutural. Para tanto, as placas com a exata localização e geometria das aberturas devem ser simuladas em software de modelagem numérica, para a definição da nova tensão interna atuante máxima. Essa tensão não pode ser superior à tensão admissível. Caso isso ocorra, há duas alternativas possíveis: a relocação das aberturas; e/ou o emprego de espessura de placas superior à empregada.

\section{Discussão}

De acordo com o dimensionamento estrutural apresentado neste trabalho, as placas polidas com $300 \mathrm{~cm}$ por $200 \mathrm{~cm}$ dos granitos Vermelho Brasília e Verde Labrador devem possuir $30 \mathrm{~mm}$ de espessura, e as placas do Cinza Castelo devem possuir $20 \mathrm{~mm}$ de espessura.

Os resultados do coeficiente de atrito mostraram que placas polidas do Vermelho Brasília e do Cinza Castelo podem ser empregadas em áreas externas, e que placas polidas do Verde Labrador têm seu uso restrito a áreas internas e secas.

De acordo com Gonzalez-Mesones (2005) e com os resultados da abrasão profunda, o monzogranito Cinza Castelo pode ser empregado em áreas de uso coletivo, e os outros dois tipos, somente em áreas de tráfego normal.

A análise petrográfica indicou que os granitos Vermelho Brasília e Cinza Castelo têm baixos níveis de microfissuramento e de alteração mineral, o que os habilita para usos em áreas externas. O Verde Labrador, pelos altos índices obtidos, é indicado apenas para áreas internas.

Essa metodologia também se aplica a placas com dimensões menores do que as apresentadas. As placas de $200 \mathrm{~cm}$ por $300 \mathrm{~cm}$ são o maior tamanho que a indústria consegue produzir sem gerar mudanças significativas nos equipamentos de corte.

\section{Conclusões}

O critério das tensões admissíveis e a teoria das estruturas em placas mostraram-se satisfatórios para representar o comportamento estático e para o dimensionamento estrutural do sistema de placas de rocha simplesmente apoiadas nos quatro lados.

As placas com dimensões $300 \mathrm{~cm}$ x $200 \mathrm{~cm}$ do sienogranito Vermelho Brasília devem ter espessura de $30 \mathrm{~mm}$, e seu uso é recomendado para ambientes internos e externos, além de permitir o tráfego normal de pessoas. As placas do charnockito Verde Labrador devem ter espessura de $30 \mathrm{~mm}$, e seu uso é recomendado apenas para ambientes internos, além de permitir o tráfego normal de pessoas. As placas do monzogranito Cinza Castelo devem possuir espessura de $20 \mathrm{~mm}$, são recomendados para ambientes internos $\mathrm{e}$ externos, e permitem intensidade de tráfego coletivo de pessoas.

\section{Referências}

\section{AMERICAN SOCIETY FOR TESTING AND \\ MATERIALS. ASTM D 7012: standard test method for compressive strength and elastic moduli of intact rock core specimens under varying states of stress and temperatures. Philadelphia, 2010.}

ASSOCIAÇÃO BRASILEIRA DA INDÚSTRIA DE ROCHAS ORNAMENTAIS. Catálogo de Rochas Ornamentais do Brasil. São Paulo: ABIRO, 2002.

\section{ASSOCIAÇÃO BRASILEIRA DE NORMAS TÉCNICAS. NBR 9062: projeto e execução de estruturas de concreto pré-moldado. Rio de Janeiro, 2006.}

\section{ASSOCIAÇÃO BRASILEIRA DE NORMAS}

TÉCNICAS. NBR 13818: placas de cerâmica para revestimentos: especificação e métodos de ensaio. 
ANEXO E: determinação da resistência à abrasão profunda. Rio de Janeiro, 1997a.

ASSOCIAÇÃO BRASILEIRA DE NORMAS TÉCNICAS. NBR 13818: placas de cerâmica para revestimentos: especificação e métodos de ensaio. ANEXO N: determinação do coeficiente de atrito. Rio de Janeiro, 1997b.

\section{ASSOCIAÇÃO BRASILEIRA DE NORMAS TÉCNICAS. NBR 15844: rochas para revestimentos: requisitos para granitos. Rio de Janeiro, 2010b.}

\section{ASSOCIAÇÃO BRASILEIRA DE NORMAS} TÉCNICAS. NBR 15845: rochas para revestimentos: métodos de ensaio. ANEXO A: análise petrográfica. Rio de Janeiro, 2010c.

ASSOCIAÇÃO BRASILEIRA DE NORMAS TÉCNICAS. NBR 15845: rochas para revestimentos: métodos de ensaio. ANEXO B: densidade aparente, porosidade aparente e absorção de água. Rio de Janeiro, 2010c.

ASSOCIAÇÃO BRASILEIRA DE NORMAS TÉCNICAS. NBR 15845: rochas para revestimentos: métodos de ensaio. ANEXO C: coeficiente de dilatação térmica linear. Rio de Janeiro, 2010a.

ASSOCIAÇÃO BRASILEIRA DE NORMAS TÉCNICAS. NBR 15845: rochas para revestimentos - Métodos de ensaio. ANEXO F: módulo de ruptura. Rio de Janeiro, 2010d.

ELLINGWOOD, B.; GALAMBOS, T. V. Probability-Based Criteria For Structural Design. Structural Safety, v. 1, n. 1, p. 15-26, 1982.

EUROPEAN COMMITTEE FOR

STANDARDIZATION. EN 1341: slabs of natural stone for external paving. requirements and test methods. CEN, Brussels, 2001a.

\section{EUROPEAN COMMITTEE FOR}

STANDARDIZATION. EN 12058: natural stone products: slabs for floors and stairs: requirements. Brussels, 2004.

EUROPEAN COMMITTEE FOR

STANDARDIZATION. EN 12825: raised Access

Floors. Brussels, $2001 \mathrm{~b}$.
FEDERAÇÃO DAS INDÚSTRIAS DO ESTADO DE SÃO PAULO. Proposta de Política

Industrial Para a Construção Civil: edificações. São Paulo: DECONCIC/FIESP, 2008.

GUIA da Construção: custos, suprimentos e soluções técnicas. São Paulo: Pini, v. 65, n. 132, jul. 2012.

GONZALEZ-MESONES, F. L. La Utilización de la Piedra Natural en la Arquitectura em el Marco de la Nueva Normativa Europea. In: INTERNATONAL CONGRESS ON DIMENSION STONES, Guapari (ES), Brasil, 2005. Proceedings... Guarapari, ES, Brasil, 2005.

LEWIS, M. D. Modern Stone Cladding: design and installation of exterior dimension stone systems. Filadélfia: ASTM, 1995. ASTM Manual Series: MNL 21.

\section{MOREIRAS, S. T. F. Estudo Sobre o Revestimento de Fachadas de Edifícios Altos Com Placas de Granitos Ornamentais. 81 f. São Carlos, 2005. Dissertação (Mestrado em Geotecnia) - Escola de Engenharia de São Carlos, Universidade de São Paulo, São Carlos, 2005.}

RIBEIRO, R. P.; PARAGUASSÚ, A. B.; RODRIGUES, J. E. Relationship Between Technological Properties and Slab Surface Roughness of Siliceous Dimension Stones. International Journal of Rock Mechanics and Mining Sciences, London, v. 45, n. 8, dec. 2008.

ROCHAS DE QUALIDADE. Editorial. São Paulo: Editores Associados, 2011. n. 216.

TABELA de Composições de Preços Para Orçamentos: TCPO. 13. ed. São Paulo: Pini, 2011. 1 CD-ROM.

TIMOSHENKO, S. P. Resistência dos Materiais. Traduzido por Domício Falcão Moreira. Rio de Janeiro: Editora ao Livro Técnico S.A., 1977. v. 2.

TIMOSHENKO, S. P.; WOINOWSKYKRIEGER, S. Theory of Plates and Shells. $2^{\text {nd }}$. ed. New York: McGraw-Hill, 1959.

\author{
Revista Ambiente Construído \\ Associação Nacional de Tecnologia do Ambiente Construído \\ Av. Osvaldo Aranha, $99-3^{\circ}$ andar, Centro \\ Porto Alegre - RS - Brasil \\ CEP 90035-190 \\ Telefone: +55 (51) 3308-4084 \\ Fax: +55 (51) 3308-4054 \\ www.seer.ufrgs.br/ambienteconstruido \\ E-mail: ambienteconstruido@ufrgs.br
}

36 Moreiras, S. T. F.; Paraguassú, A. B. 